\section{Re: Living on the Edge}

To the Editor: Dr. Adam Goldstein's essay is remarkable in many ways, not the least of which is his ability to articulate the internal conflicts, the struggles with helplessness and ineffectualness, and the need to tell others what we know about our patients without violating the confidentiality that is central to doctoring. The lessons from this story are not simple, or simply taught. We need to let patients find hope for themselves even when we see little for them, trust them to ask what they need from us, and be humble about what we can give back to them. While we may see Virginia as needing intervention in her many seemingly self-inflicted wounds, Dr. Goldstein gives her what she needs most-kindness, compassion, and support without blame. The irony of an abuser telling Dr. Goldstein about how his wife respected him as her doctor only hints at the enormity of the conflict that Dr. Goldstein must have felt; the doctor knew things about this man and the lies the man told that could never be shared, knew secrets of his life and his wife's life that could not be communicated in a problem list. It is good that he wrote this-for Virginia, for us, and for Dr. Goldstein himself. Sometimes things feel too heavy to bear in the work we do, and storytelling is one way to be able to understand and to keep working.

John J. Frey III, MD

University of Wisconsin-Madison Department of Family Medicine

Madison, Wisconsin.

jfrey@fammed.wisc.edu

doi: $10.3122 /$ jabfm.2011.05.110136

The above letter was referred to the author of the article in question, who offers the following reply. 